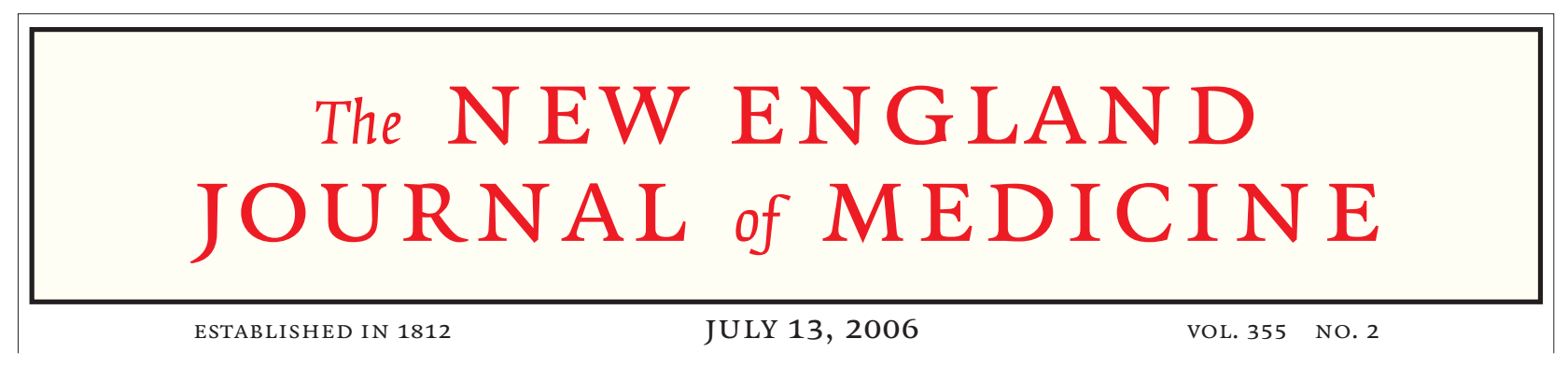

\title{
Effects of Raloxifene on Cardiovascular Events and Breast Cancer in Postmenopausal Women
}

\author{
Elizabeth Barrett-Connor, M.D., Lori Mosca, M.D., Ph.D., M.P.H., Peter Collins, M.D., Mary Jane Geiger, M.D., Ph.D., \\ Deborah Grady, M.D., M.P.H., Marcel Kornitzer, M.D., Michelle A. McNabb, M.S., and Nanette K. Wenger, M.D., \\ for the Raloxifene Use for The Heart (RUTH) Trial Investigators*
}

\author{
ABSTRACT
}

\section{BACKGROUND}

The effect of raloxifene, a selective estrogen-receptor modulator, on coronary heart disease (CHD) and breast cancer is not established.

\section{METHODS}

We randomly assigned 10,101 postmenopausal women (mean age, 67.5 years) with CHD or multiple risk factors for CHD to $60 \mathrm{mg}$ of raloxifene daily or placebo and followed them for a median of 5.6 years. The two primary outcomes were coronary events (i.e., death from coronary causes, myocardial infarction, or hospitalization for an acute coronary syndrome) and invasive breast cancer.

\section{RESULTS}

As compared with placebo, raloxifene had no significant effect on the risk of primary coronary events (533 vs. 553 events; hazard ratio, 0.95; 95 percent confidence interval, 0.84 to 1.07), and it reduced the risk of invasive breast cancer ( 40 vs. 70 events; hazard ratio, 0.56 ; 95 percent confidence interval, 0.38 to 0.83 ; absolute risk reduction, 1.2 invasive breast cancers per 1000 women treated for one year); the benefit was primarily due to a reduced risk of estrogen-receptor-positive invasive breast cancers. There was no significant difference in the rates of death from any cause or total stroke according to group assignment, but raloxifene was associated with an increased risk of fatal stroke (59 vs. 39 events; hazard ratio, 1.49; 95 percent confidence interval, 1.00 to 2.24; absolute risk increase, 0.7 per 1000 woman-years) and venous thromboembolism (103 vs. 71 events; hazard ratio, 1.44; 95 percent confidence interval, 1.06 to 1.95; absolute risk increase, 1.2 per 1000 woman-years). Raloxifene reduced the risk of clinical vertebral fractures (64 vs. 97 events; hazard ratio, 0.65 ; 95 percent confidence interval, 0.47 to 0.89 ; absolute risk reduction, 1.3 per 1000).

\section{CONCLUSIONS}

Raloxifene did not significantly affect the risk of CHD. The benefits of raloxifene in reducing the risks of invasive breast cancer and vertebral fracture should be weighed against the increased risks of venous thromboembolism and fatal stroke. (ClinicalTrials.gov number, NCT00190593.)
From the Department of Family and Preventive Medicine, University of California, San Diego, La Jolla (E.B.-C.); the Department of Medicine, Columbia University College of Physicians and Surgeons, New York (L.M.); the Department of Cardiac Medicine, Royal Brompton Hospital and National Heart and Lung Institute, Imperial College London, London (P.C.); Lilly Research Laboratories, Eli Lilly, Indianapolis (M.J.G., M.A.M.); the Departments of Epidemiology and Biostatistics and Medicine, University of California, San Francisco, and the San Francisco Veterans Affairs Medical Center, San Francisco (D.G.); the Department of Epidemiology and Health Promotion, School of Public Health, Brussels Free University, Brussels (M.K.); and Emory University School of Medicine, Atlanta (N.K.W.). Address reprint requests to Dr. Barrett-Connor at the Department of Family and Preventive Medicine, University of California, San Diego, 9500 Gilman Dr., La Jolla, CA 92093-0607, or at ebarrettconnor@ucsd.edu.

*Investigators participating in the RUTH trial are listed in the Appendix.

N Engl J Med 2006;355:125-37. Copyright (c) 2006 Massachusetts Medical Society. 
$\mathrm{R}$ ALOXIFENE IS A NONSTEROIDAL SELECtive estrogen-receptor modulator (SERM) that binds to the estrogen receptor, leading to estrogen-agonist effects in some tissues and estrogen-antagonist effects in others. ${ }^{1}$ Raloxifene therapy has been associated with improvement in the levels of serum lipoprotein cholesterol, ${ }^{2,3}$ fibrinogen, ${ }^{3}$ and homocysteine. ${ }^{4}$ The favorable effect of raloxifene on markers of cardiovascular risk, coupled with evidence from observational studies that treatment with estrogen was associated with a reduced risk of coronary heart disease (CHD) in postmenopausal women, ${ }^{5,6}$ led to the design of the Raloxifene Use for The Heart (RUTH) trial to determine the effect of raloxifene on clinical coronary events. After the RUTH trial began in 1998, results of the Heart and Estrogen/Progestin Replacement Study (HERS $^{7}$ and the Women's Health Initiative (WHI) clinical trials ${ }^{8,9}$ showed no reduction in the risk of CHD after treatment with estrogen or estrogen plus progestin. A secondary analysis of data from the Multiple Outcomes of Raloxifene Evaluation (MORE) trial (an osteoporosis-treatment trial) showed no significant overall effect of raloxifene on cardiovascular events but suggested a reduced risk among women who were at increased risk for cardiovascular events. ${ }^{10}$

Raloxifene has antiestrogenic effects in the breast, competitively blocking estrogen-induced DNA transcription ${ }^{11}$ and inhibiting the growth of estrogen-stimulated mammary cancers in animals. ${ }^{12}$ After the RUTH trial began, a secondary analysis of data from the MORE trial showed that raloxifene reduced the risk of invasive breast cancer by 72 percent. $^{13}$

We conducted the RUTH trial to assess the risks and benefits of treatment with raloxifene in women with or at increased risk for CHD, with the primary aims of determining effects on coronary outcomes and invasive breast cancer.

\section{METHODS}

RUTH was an international, multicenter, randomized, double-blind, placebo-controlled trial. A detailed description of the design and study population has been published elsewhere. ${ }^{14,15}$ The two primary objectives were to determine the effect of raloxifene as compared with placebo on the incidence of coronary events (i.e., death from coronary causes, nonfatal [including silent] myocardial infarction, or hospitalization for an acute coronary syndrome other than myocardial infarction) and invasive breast cancer.

The executive committee developed the protocol in collaboration with the sponsor. An independent data and safety monitoring board with independent statistical support performed interim analyses of safety and efficacy. The data were analyzed by the sponsor according to the prespecified analysis plan. The executive committee had unrestricted request-based access to data, which were retained by the sponsor. All authors were involved in interpreting the data and drafting the manuscript and vouch for the accuracy and completeness of the reported data. Data reported are those available as of February 2, 2006.

The protocol was approved by the ethics review board at each investigative site. All women gave written informed consent for participation in accordance with the principles of the Declaration of Helsinki.

\section{STUDY POPULATION}

Between June 1998 and August 2000, 10,101 postmenopausal women were randomly assigned to treatment or placebo at 177 sites in 26 countries. Eligible women were 55 years of age or older, were one year or more postmenopausal, and had established CHD or were at increased risk for CHD. ${ }^{14}$ Participants were required to have a cardiovascular risk score of 4 or more, according to a point system that takes into account the presence of the following ${ }^{14}$ : established CHD (4 points), arterial disease of the leg (4 points), an age of at least 70 years ( 2 points), diabetes mellitus ( 3 points), cigarette smoking (1 point), hypertension (1 point), and hyperlipidemia (1 point).

Exclusion criteria were a myocardial infarction, coronary-artery bypass grafting, or percutaneous coronary intervention within three months before randomization; a history of cancer or venous thromboembolism; a life expectancy of less than five years; unexplained uterine bleeding within six months before randomization; New York Heart Association class III or IV heart failure; chronic liver or renal disease; use of oral or transdermal estrogens within six months before randomization; or current use of other sex hormones or SERMs.

\section{TREATMENT AND STUDY PROCEDURES}

Eligible women were randomly assigned to $60 \mathrm{mg}$ of raloxifene a day orally (Evista, Eli Lilly) or to 
identical-appearing placebo (Fig. 1). Randomization was performed with the use of an interactive voice-response telephone system stratified according to study site. At each biannual visit or telephone contact, adverse events, outcomes, and adherence to study medication were ascertained. Electrocardiography (ECG) was performed at baseline, year 2, year 4, and the final visit. Mammography and clinical breast examinations were performed at randomization and every two years thereafter. Serum lipid levels were measured after an overnight fast at baseline, year 1 , year 5 , and the final visit.

Investigators, participants, laboratory staff, and the sponsor (Eli Lilly) were blinded to participants' treatment assignment. Treatment assignment was revealed to investigators only for reasons of participants' safety. The study drug was permanently discontinued when the treatment assignment was revealed to a participant (26 women) or breast cancer or venous thromboembolism was diagnosed. The study drug was temporarily discontinued during periods of prolonged immobilization or if the participant took estro- gen-containing preparations, other hormonal agents, or SERMs.

\section{OUTCOMES}

Reported outcomes of coronary events, breast cancer, stroke, venous thromboembolism, and death were adjudicated by committees of experts who were unaware of participants' treatment assignment and who were not employees of the sponsor. Employees of the sponsor, who were unaware of the treatment assignment, adjudicated the secondary outcomes of fracture, myocardial revascularization, noncoronary arterial revascularization, amputation of a leg, and hospitalization for any cause.

\section{Coronary Events}

The primary coronary outcome was defined as the first of any of the following events: death from coronary causes (i.e., acute myocardial infarction, sudden or unwitnessed death, heart failure, or death related to a coronary-artery procedure), myocardial infarction, or hospitalization for an acute coronary syndrome other than myo-

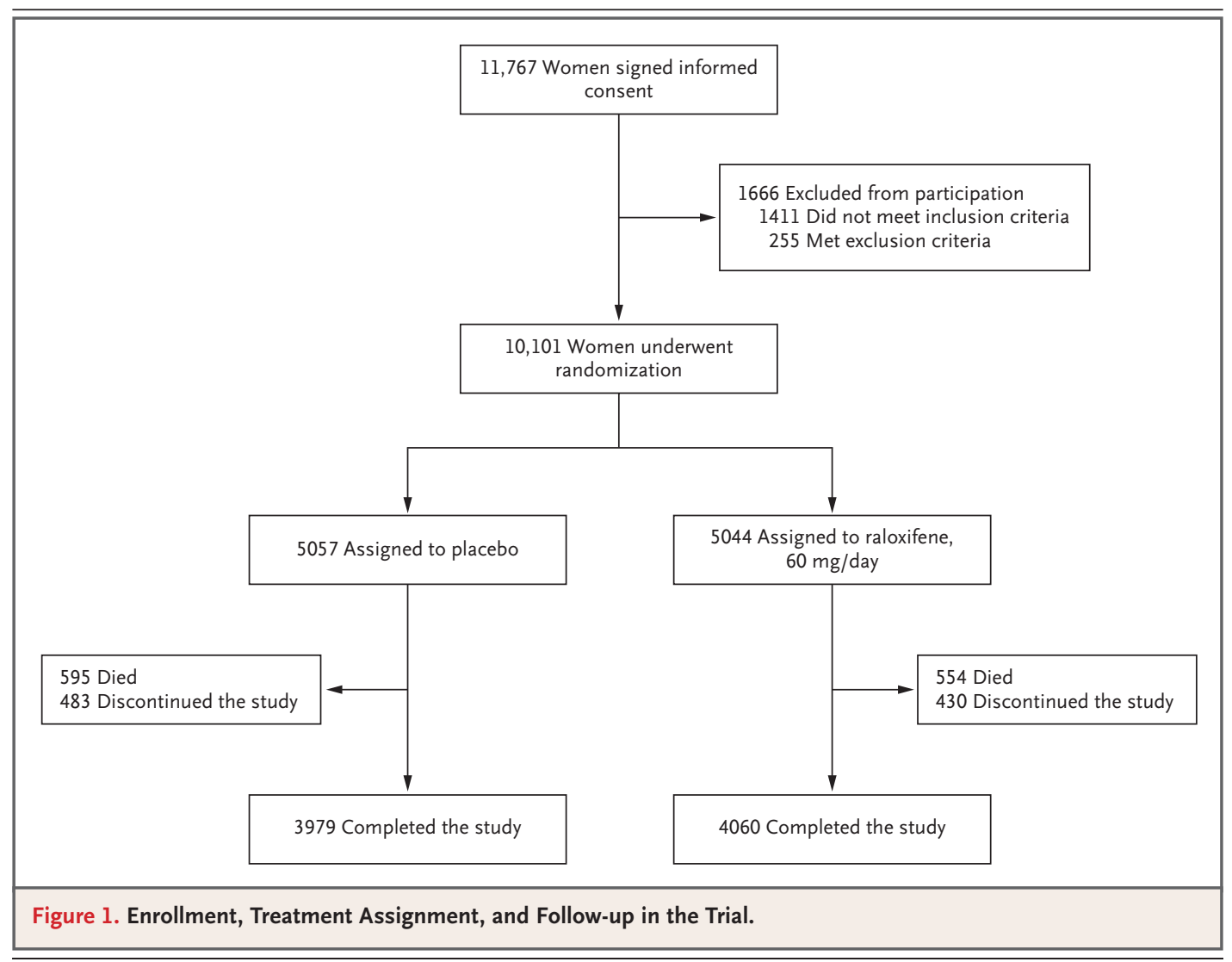


cardial infarction. ${ }^{14}$ Myocardial infarction was diagnosed if at least one of the following was present: ischemic symptoms and abnormal levels of cardiac enzymes, with or without new, equivocal changes on ECG; a new pathological Q wave, with or without ischemic symptoms or abnormal levels of cardiac enzymes; and new pathological $\mathrm{Q}$ waves or markedly abnormal levels of cardiac enzymes after invasive coronary procedures. Hospitalization for an acute coronary syndrome was defined as hospitalization for or the development during hospitalization of cardiac symptoms with new changes in the ST-T segment on ECG or abnormal levels of cardiac enzymes or troponin.

\section{Breast Cancer}

Breast cancers were confirmed by pathology reports. They were classified as invasive or noninvasive and according to estrogen-receptor status.

\section{Secondary Outcomes}

Secondary mortality outcomes were death from coronary causes, death from cardiovascular causes (death from coronary causes and death from noncoronary cardiovascular causes such as cerebrovascular, venous thromboembolic, atherosclerotic noncoronary vascular disease, and other cardiovascular causes), and death from any cause (death from cardiovascular causes and death from noncardiovascular causes such as cancer, accident, suicide, homicide, or any other cause). The cause of death was assigned on the basis of available clinical information, the death certificate, or autopsy. Stroke was defined as the rapid onset of a persistent neurologic deficit lasting more than 24 hours, in most cases supported by findings on imaging studies. A venous thromboembolic event required clinical symptoms supported by relevant diagnostic studies. Revascularization included myocardial and noncoronary arterial revascularizations. Nontraumatic amputations of the leg included those above and those below the knee. All reported clinical fractures were validated by review of radiology reports. Hospitalization for any cause was defined as hospitalization for at least 24 hours.

\section{ADVERSE EVENTS}

Adverse events were recorded by the investigator at each visit on the basis of unsolicited reporting by the participant. All adverse events were classified according to the Medical Dictionary for Regula- tory Activities (MedDRA, a registered trademark of the International Federation of Pharmaceutical Manufacturers and Associations), developed under the auspices of the International Conference on Harmonization of Technical Requirements for Registration of Pharmaceuticals for Human Use. Common adverse events were defined as events at the MedDRA Preferred Term level occurring in at least 2 percent of women assigned to raloxifene. Special search categories were established with the use of MedDRA terms to comprehensively describe adverse events of potential relevance to SERMs or hormone therapy.

Serious adverse events were defined as events that were life-threatening, severe, or permanently disabling; cancer; or clinically significant for any other reason. These were identified as primary or secondary outcomes or, in the case of cancer, through a special search category established with the use of MedDRA terms.

\section{STATISTICAL ANALYSIS}

Comparisons of baseline characteristics between treatment groups were performed with the use of one-way analysis of variance for continuous variables and chi-square tests for categorical variables. Primary analyses used time-to-event methods on the basis of the intention-to-treat principle. Data on women who did not have an event were censored on the date when study information was last collected or on the date of death. Relative incidences of the primary outcomes of coronary events and invasive breast cancer were compared with the use of a log-rank test. Unadjusted Cox proportionalhazards models were used to estimate hazard ratios with 95 percent confidence intervals for the primary and secondary outcomes.

Adverse events were analyzed with a CochranMantel-Haenszel test stratified according to country. If fewer than five events occurred, no statistical test was performed. Baseline laboratory values and percentage change from baseline to one year were analyzed with the use of an unadjusted ranked one-way analysis of variance.

Secondary analyses were performed for the primary outcomes in an "as-treated" population, defined as women who were at least 70 percent adherent to the study treatment on the basis of the pill count. The primary outcome of coronary events was assessed separately for those with CHD and for those at increased risk for CHD with the use of Cox proportional-hazards models. 
All analyses were prespecified, except the interaction test of the primary outcome of coronary events in women with established CHD as compared with those at increased risk for CHD. Reported $\mathrm{P}$ values are two-sided. Statistical analyses were performed with the use of SAS software, version 8.2 (SAS Institute).

The power calculations were based on assumptions of a 20.0 percent relative reduction in the risk of coronary events and a 58.5 percent relative reduction in the risk of invasive breast cancer with raloxifene, given a statistical power of 80 percent and a two-sided alpha level of 0.0423 for coronary events and 0.008 for invasive breast cancer. Other outcomes were tested at a significance level of 0.05 , except interaction effects, which were tested at a significance level of 0.10 . No adjustments were made for multiple comparisons.

\section{RESULTS}

For both treatment groups, the median duration of follow-up was 5.56 years (range, 0.01 to 7.06 ) and the median exposure to the study drug was 5.05 years. The study was completed by 79 percent of women in the placebo group and 80 percent in the raloxifene group $(\mathrm{P}=0.02)$. Overall, 71 percent of women in the placebo group and 70 percent in the raloxifene group took at least 70 percent of the assigned medication and were classified as adherent to treatment $(\mathrm{P}=0.62)$.

The treatment groups were similar with respect to baseline characteristics (Table 1), except the raloxifene group had a slightly higher cardiovascular risk score and a higher proportion of women reporting coronary-artery bypass grafting. During the trial, both the placebo and raloxifene groups had increases in the use of statins (21 percent and 19 percent, respectively), antihypertensive agents ( 6 percent and 7 percent), and aspirin (13 percent and 15 percent) ( $P>0.05$ for each comparison).

\section{PRIMARY OUTCOMES}

There was no significant difference between the raloxifene group and the placebo group in the incidence of the primary outcome of death from coronary causes, nonfatal myocardial infarction, or hospitalization for an acute coronary syndrome (hazard ratio, 0.95; 95 percent confidence interval, 0.84 to 1.07) (Table 2 and Fig. 2A), or for death from coronary causes, nonfatal myocardial infarction, or hospitalization for an acute coronary syndrome individually. The effect of treatment on the primary outcome of coronary events did not differ significantly among women with established CHD (hazard ratio, 0.97; 95 percent confidence interval, 0.83 to 1.12 ) or women at increased risk for CHD (hazard ratio, 0.91; 95 percent confidence interval, 0.74 to 1.11 ) (P value for the interaction $=0.64$ ). There were 18 other prespecified subgroup analyses for the primary coronary outcome (including age and the presence or absence of risk factors for CHD); there were no significant treatment-group interactions for any subgroup $(P>0.10)$. The results of astreated analyses were similar to those of the intention-to-treat analyses for the primary coronary outcome (hazard ratio for the comparison of the raloxifene group with the placebo group, 0.96; 95 percent confidence interval, 0.83 to 1.12; $\mathrm{P}=0.61)$ and its individual components $(\mathrm{P}>0.05$ for each comparison).

Raloxifene reduced the incidence of the primary outcome of invasive breast cancer (hazard ratio, 0.56; 95 percent confidence interval, 0.38 to 0.83) (Table 2 and Fig. 2B), primarily because of a reduction in estrogen-receptor-positive invasive breast cancer (Table 2). The absolute risk reduction per 1000 women treated with raloxifene for one year was 1.2 cases of invasive breast cancer and 1.2 cases of estrogen-receptor-positive invasive breast cancer. The results of the as-treated analysis for invasive breast cancer were similar (hazard ratio for the comparison of the raloxifene group with the placebo group, 0.61; 95 percent confidence interval, 0.39 to $0.95 ; \mathrm{P}=0.03$ ). There was no significant difference between treatment groups in the incidence of estrogen-receptor-negative invasive breast cancer (Table 2).

The effect of treatment on invasive breast cancer did not differ significantly among women with a five-year estimated risk of invasive breast cancer of less than 1.66 percent on the basis of the Gail score ${ }^{16}$ (hazard ratio, 0.49; 95 percent confidence interval, 0.28 to 0.88 ) or 1.66 percent or more (hazard ratio, 0.65 ; 95 percent confidence interval, 0.38 to 1.09 ; P value for the interaction $=0.50$ ). There were eight other prespecified subgroup analyses for invasive breast cancer; there were no significant treatment-group interactions for any subgroup $(\mathrm{P}>0.1)$ except the ovariectomy subgroup analysis $(\mathrm{P}=0.07)$. 


\begin{tabular}{|c|c|c|c|}
\hline Characteristic & $\begin{array}{l}\text { Raloxifene } \\
(\mathrm{N}=5044)\end{array}$ & $\begin{array}{c}\text { Placebo } \\
(\mathrm{N}=5057)\end{array}$ & $P$ Value \\
\hline Age (yr) & $67.5 \pm 6.6$ & $67.5 \pm 6.7$ & 0.86 \\
\hline Age $\geq 70$ yr (\%) & 38.7 & 39.2 & 0.63 \\
\hline White race $(\%) \dagger$ & 84.0 & 84.0 & 0.96 \\
\hline Region (\%) & & & 1.00 \\
\hline Western Europe & 46.3 & 46.3 & \\
\hline Eastern Europe & 22.9 & 22.9 & \\
\hline Latin or South America & 13.6 & 13.5 & \\
\hline North America & 10.2 & 10.2 & \\
\hline Asia Pacific & 4.9 & 5.0 & \\
\hline Africa & 2.1 & 2.2 & \\
\hline Body-mass indext & $28.8 \pm 5.2$ & $28.7 \pm 5.1$ & 0.27 \\
\hline Waist circumference $(\mathrm{cm})$ & $93.9 \pm 13.2$ & $93.9 \pm 13.1$ & 0.86 \\
\hline Current smoker (\%)』 & 12.0 & 12.8 & 0.22 \\
\hline Alcohol consumption (\%) & 42.7 & 43.1 & 0.68 \\
\hline Vigorous physical activity $\geq 3$ times per week (\%) & 18.8 & 18.3 & 0.57 \\
\hline \multicolumn{4}{|l|}{ Previous use of therapy (\%) } \\
\hline Estrogen & 14.0 & 14.0 & 0.93 \\
\hline Estrogen plus progestin & 5.7 & 6.5 & 0.10 \\
\hline Hysterectomy (\%) & 22.7 & 23.3 & 0.48 \\
\hline Postmenopausal years & $19.3 \pm 8.8$ & $19.5 \pm 8.8$ & 0.32 \\
\hline Presence of diabetes mellitus (\%) & 45.7 & 45.8 & 0.89 \\
\hline Systolic blood pressure (mm Hg) & $145.8 \pm 20.3$ & $145.4 \pm 20.1$ & 0.37 \\
\hline Diastolic blood pressure ( $\mathrm{mm} \mathrm{Hg}$ ) & $82.0 \pm 10.5$ & $82.0 \pm 10.4$ & 0.98 \\
\hline Hypertension (\%)\| & 77.9 & 77.8 & 0.94 \\
\hline Hyperlipidemia (\%) & 73.3 & 73.6 & 0.75 \\
\hline History of coronary artery disease (\%) †† & 50.3 & 49.4 & 0.34 \\
\hline Arterial disease affecting the legs (\%) & 10.8 & 10.7 & 0.89 \\
\hline Cardiovascular risk scoretr & $7.9 \pm 4.0$ & $7.8 \pm 3.7$ & 0.03 \\
\hline Cardiovascular risk score category (\%) & & & 0.68 \\
\hline $4-6$ & 50.1 & 50.6 & \\
\hline$>6$ & 49.5 & 49.1 & \\
\hline Five-year predicted risk of invasive breast cancer (\%) d] & $1.73 \pm 0.76$ & $1.73 \pm 0.77$ & 0.85 \\
\hline
\end{tabular}

\section{SECONDARY OUTCOMES}

The overall incidence of stroke did not differ significantly between treatment groups, but the incidence of fatal stroke was 49 percent higher in the raloxifene group than in the placebo group (absolute risk increase, 0.7 per 1000 woman-years). The incidence of venous thromboembolic events was 44 percent higher in the raloxifene group than in the placebo group (absolute risk increase, 1.2 per 1000 woman-years). There was a 33 percent lower incidence of all breast cancers (absolute risk reduction, 0.9 per 1000 woman-years) and a 35 percent lower incidence of clinical vertebral fractures (absolute risk reduction, 1.3 per 1000 woman-years) in the raloxifene group (Table 2).

There was no significant difference between treatment groups in the rates of death from any cause or overall death from cardiovascular causes. The incidence of death from noncardiovascular causes was lower in the raloxifene group than in 


\begin{tabular}{|c|c|c|c|}
\hline Characteristic & $\begin{array}{l}\text { Raloxifene } \\
(\mathrm{N}=5044)\end{array}$ & $\begin{array}{l}\text { Placebo } \\
(\mathrm{N}=5057)\end{array}$ & P Value \\
\hline $\begin{array}{l}\text { Five-year predicted risk of invasive breast cancer } \geq 1.66 \\
\text { percent }(\%) \iint\end{array}$ & 41.7 & 41.2 & 0.61 \\
\hline Family history of breast cancer (\%) & 9.8 & 9.7 & 0.85 \\
\hline \multicolumn{4}{|l|}{ Medication use at baseline (\%) } \\
\hline Statin & 47.2 & 46.7 & 0.59 \\
\hline Antihypertensive agent & 89.6 & 89.4 & 0.83 \\
\hline Aspirin & 56.4 & 56.7 & 0.82 \\
\hline Oral hypoglycemic agent & 34.0 & 33.8 & 0.84 \\
\hline Insulin & 13.8 & 14.4 & 0.39 \\
\hline \multicolumn{4}{|l|}{ Fasting serum glucose level (mg/dl) } \\
\hline Women with diabetes mellitus & $180.7 \pm 71.7$ & $181.1 \pm 71.1$ & 0.66 \\
\hline Women without diabetes mellitus & $102.1 \pm 16.0$ & $102.1 \pm 16.1$ & 0.67 \\
\hline LDL cholesterol level (mg/dl) & $121.7 \pm 37.1$ & $122.1 \pm 37.4$ & 0.67 \\
\hline HDL cholesterol level (mg/dl) & $52.3 \pm 14.2$ & $52.6 \pm 14.4$ & 0.61 \\
\hline
\end{tabular}

* Plus-minus values are means \pm SD. Because of rounding, percentages may not total 100. To convert values for glucose to millimoles per liter, multiply by 0.05551 . To convert values for cholesterol to millimoles per liter, multiply by 0.0259. LDL denotes low-density lipoprotein, and HDL high-density lipoprotein.

$\uparrow$ Race or ethnic group was self-designated.

Body-mass index is the weight in kilograms divided by the square of the height in meters.

$\int$ Smoking was defined as self-reported smoking of an average of at least 10 cigarettes a day during the six months before visit 1.

I Diabetes was defined as self-reported diabetes mellitus and the use of oral hypoglycemic medication or insulin, or as a fasting serum glucose level of more than $140 \mathrm{mg}$ per deciliter at visit 1.

|| Hypertension was defined as self-reported hypertension and the use of antihypertensive agents, or systolic blood pressure greater than $160 \mathrm{~mm} \mathrm{Hg}$ or diastolic blood pressure greater than $95 \mathrm{~mm} \mathrm{Hg}$ on at least two measurements.

$*$ Hyperlipidemia was defined as the use of lipid-lowering medications or a fasting LDL cholesterol level of more than $160 \mathrm{mg}$ per deciliter, or a fasting HDL cholesterol level of less than $45 \mathrm{mg}$ per deciliter, with a fasting triglyceride level of more than $250 \mathrm{mg}$ per deciliter.

t† A history of coronary artery disease includes previous myocardial infarction, coronary-artery bypass grafting, percutaneous coronary intervention, or angina with documented coronary heart disease.

+ The cardiovascular risk score was calculated on the basis of the presence of the following risk factors for a major coronary event ${ }^{14}$ : established coronary heart disease (4 points), arterial disease involving the legs (4 points), an age of at least 70 years ( 2 points), diabetes mellitus ( 3 points), cigarette smoking (1 point), hypertension (1 point), and hyperlipidemia (1 point).

$\iint$ The five-year predicted risk was calculated on the basis of the presence or absence of recognized risk factors for breast cancer, with the use of the Gail model. ${ }^{16}$

the placebo group (absolute risk reduction, 1.7 per 1000 woman-years); no specific disease category explained this finding. Fewer women in the raloxifene group than in the placebo group had one or more hospitalizations for any cause (52 percent vs. 54 percent; hazard ratio, 0.91 ; 95 percent confidence interval, 0.87 to $0.96 ; \mathrm{P}=0.001$ ).

\section{ADVERSE EVENTS}

There was no significant difference between the treatment groups in the number of women with one or more reported adverse events (93 percent in both groups, $\mathrm{P}=0.71$ ). More women in the raloxifene group than in the placebo group perma- nently discontinued use of the study drug because of an adverse event (22 percent vs. 20 percent, $\mathrm{P}=0.01$ ).

Four common adverse events (an acute coronary syndrome, anxiety, constipation, and osteoporosis) were reported more frequently in the placebo group than in the raloxifene group, and seven (arthritis, cholelithiasis, dyspepsia, hot flush, intermittent claudication, muscle spasm, and peripheral edema) were reported more frequently in the raloxifene group than in the placebo group $(\mathrm{P} \leq 0.05)$. Hot flushes, leg cramps, peripheral edema, and gallbladder disease, all special search categories, were more common in women assigned 


\begin{tabular}{|c|c|c|c|c|}
\hline End Point & $\begin{array}{l}\text { Raloxifene } \\
(\mathrm{N}=5044)\end{array}$ & $\begin{array}{l}\text { Placebo } \\
(\mathrm{N}=5057)\end{array}$ & $\begin{array}{l}\text { Hazard Ratio } \\
(95 \% \mathrm{Cl})\end{array}$ & $P$ Value \\
\hline \multicolumn{5}{|c|}{ no. of events (annualized rate [\%]) } \\
\hline \multicolumn{5}{|l|}{ Cardiovascular } \\
\hline Combined coronary end point & $533(2.06)$ & $553(2.16)$ & $0.95(0.84-1.07)$ & 0.40 \\
\hline Death from coronary causes & $253(0.95)$ & $273(1.03)$ & $0.92(0.77-1.09)$ & 0.31 \\
\hline Nonfatal myocardial infarction $\uparrow$ & $183(0.69)$ & $208(0.80)$ & $0.87(0.71-1.06)$ & 0.16 \\
\hline $\begin{array}{l}\text { Hospitalization for an acute coronary syndrome other than myocardial } \\
\text { infarction }\end{array}$ & $169(0.64)$ & $185(0.71)$ & $0.90(0.73-1.11)$ & 0.34 \\
\hline $\begin{array}{l}\text { Death from cardiovascular causes, nonfatal myocardial infarction, hospital- } \\
\text { ization for an acute coronary syndrome, or stroke }\end{array}$ & 789 (3.09) & $767(3.05)$ & $1.02(0.92-1.12)$ & 0.76 \\
\hline $\begin{array}{l}\text { Death from cardiovascular causes, nonfatal myocardial infarction, hospital- } \\
\text { ization for an acute coronary syndrome, myocardial revasculariza- } \\
\text { tion, or stroke }\end{array}$ & $1067(4.33)$ & $1041(4.28)$ & $1.01(0.93-1.10)$ & 0.80 \\
\hline Stroke & $249(0.95)$ & $224(0.86)$ & $1.10(0.92-1.32)$ & 0.30 \\
\hline Hemorrhagic & $18(0.07)$ & $30(0.11)$ & $0.59(0.33-1.06)$ & 0.07 \\
\hline Ischemic & $198(0.75)$ & $171(0.65)$ & $1.15(0.93-1.41)$ & 0.19 \\
\hline Undetermined & $39(0.15)$ & $30(0.11)$ & $1.28(0.80-2.07)$ & 0.30 \\
\hline Venous thromboembolic event & $103(0.39)$ & $71(0.27)$ & $1.44(1.06-1.95)$ & 0.02 \\
\hline Pulmonary embolism & $36(0.14)$ & $24(0.09)$ & $1.49(0.89-2.49)$ & 0.13 \\
\hline Deep-vein thrombosis & $65(0.24)$ & $47(0.18)$ & $1.37(0.94-1.99)$ & 0.10 \\
\hline All revascularizations & $611(2.44)$ & $615(2.49)$ & $0.98(0.88-1.10)$ & 0.73 \\
\hline Nontraumatic amputation of the leg & $41(0.15)$ & $44(0.17)$ & $0.92(0.60-1.41)$ & 0.70 \\
\hline \multicolumn{5}{|l|}{ Breast cancer } \\
\hline Invasive breast cancer & $40(0.15)$ & $70(0.27)$ & $0.56(0.38-0.83)$ & 0.003 \\
\hline Estrogen-receptor-positive & $25(0.09)$ & $55(0.21)$ & $0.45(0.28-0.72)$ & $<0.001$ \\
\hline Estrogen-receptor-negative & $13(0.05)$ & $9(0.03)$ & $1.44(0.61-3.36)$ & 0.40 \\
\hline Unknown estrogen-receptor status & $2(0.007)$ & $6(0.02)$ & $0.33(0.07-1.63)$ & 0.15 \\
\hline Noninvasive breast cancert & $11(0.04)$ & $5(0.02)$ & $2.17(0.75-6.24)$ & 0.14 \\
\hline All breast cancers $\mathbb{}$ & $52(0.20)$ & $76(0.29)$ & $0.67(0.47-0.96)$ & 0.03 \\
\hline \multicolumn{5}{|l|}{ Fracture } \\
\hline Clinical nonvertebral & $428(1.67)$ & $438(1.73)$ & $0.96(0.84-1.10)$ & 0.59 \\
\hline Clinical vertebral & $64(0.24)$ & $97(0.37)$ & $0.65(0.47-0.89)$ & 0.007 \\
\hline \multicolumn{5}{|l|}{ Death } \\
\hline Any cause & $554(2.07)$ & $595(2.25)$ & $0.92(0.82-1.03)$ & 0.16 \\
\hline Cardiovascular cause & $362(1.35)$ & $355(1.34)$ & $1.01(0.87-1.17)$ & 0.91 \\
\hline Noncoronary & $107(0.40)$ & $81(0.31)$ & $1.31(0.98-1.74)$ & 0.07 \\
\hline Cerebrovascular (stroke) & $59(0.22)$ & $39(0.15)$ & $1.49(1.00-2.24)$ & 0.05 \\
\hline Venous thromboembolism & $10(0.04)$ & $5(0.02)$ & $1.98(0.68-5.79)$ & 0.20 \\
\hline Noncardiovascular cause & $188(0.70)$ & $231(0.87)$ & $0.80(0.66-0.98)$ & 0.03 \\
\hline Cancers & $97(0.36)$ & $103(0.39)$ & $0.93(0.70-1.23)$ & 0.61 \\
\hline Noncancer & $91(0.34)$ & $128(0.48)$ & $0.70(0.54-0.92)$ & 0.01 \\
\hline Cause unavailable & $4(0.02)$ & $9(0.03)$ & $0.44(0.14-1.43)$ & 0.16 \\
\hline
\end{tabular}

* The primary coronary end point was death from coronary causes, nonfatal myocardial infarction, or hospitalization for an acute coronary syndrome, other than myocardial infarction, whichever occurred first. For any participant with multiple coronary events, each first event in each subcategory was counted separately. $\mathrm{Cl}$ denotes confidence interval.

$T$ This end point includes 9 women in the placebo group and 24 in the raloxifene group who had silent myocardial infarction.

All noninvasive breast cancers were ductal carcinoma in situ.

$\int$ This end point includes invasive and noninvasive breast cancers, plus one additional breast cancer in each treatment group for which the invasiveness could not be determined.

I For four deaths in the placebo group and four in the raloxifene group, the strokes reported by the investigator were not adjudicated as strokes by the stroke committee. For one death in the raloxifene group, the investigator did not report the stroke as an end point, and it was therefore not reviewed by the stroke committee. These nine strokes were not included in the analysis of the end point of stroke. 


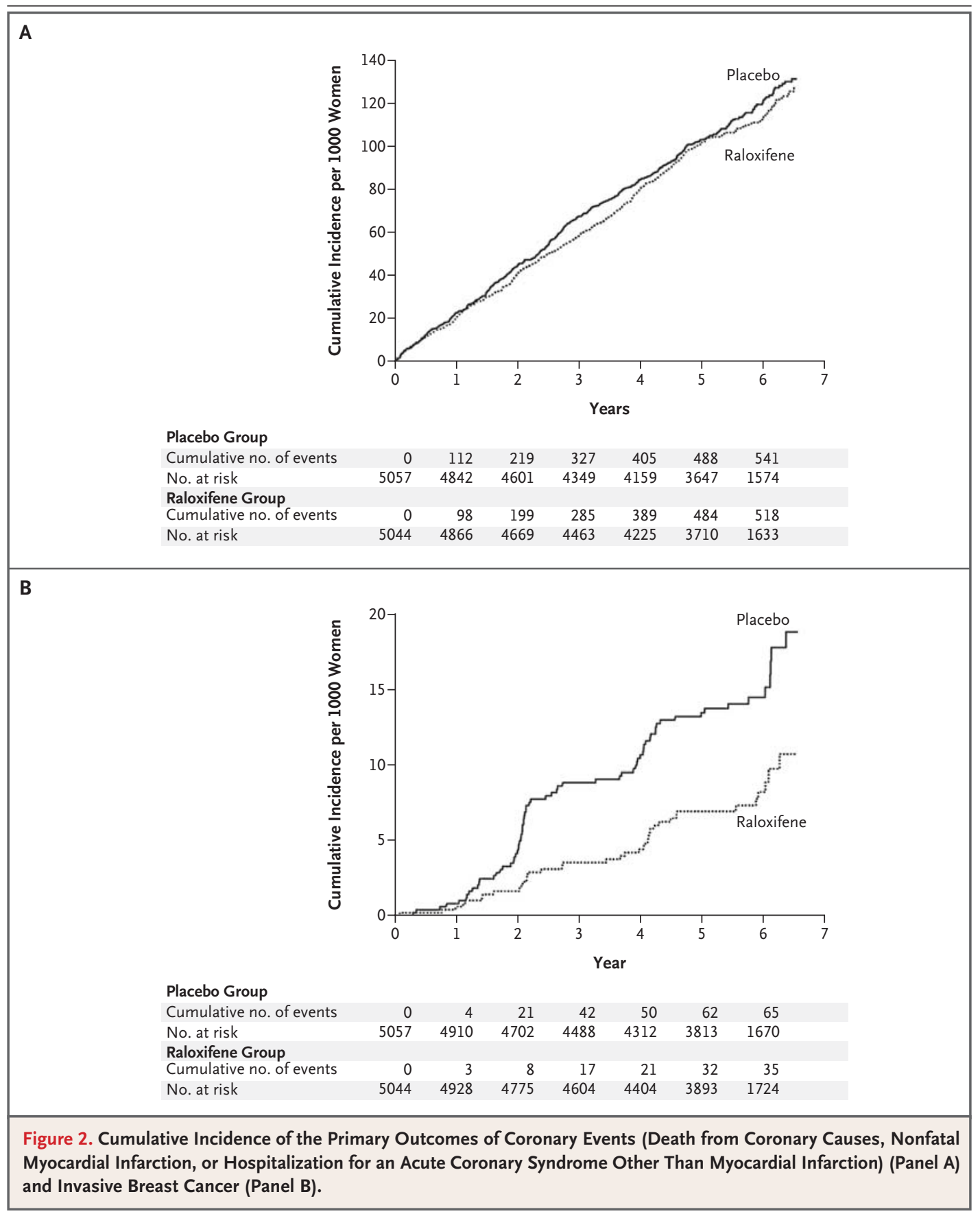

to raloxifene than to placebo (Table 3). The rates of cholecystectomy did not differ significantly between the treatment groups $(\mathrm{P}=0.25)$. The incidences of endometrial cancer and all cancers other than breast cancer did not differ significantly between treatment groups.

\section{CHANGES IN LIPOPROTEIN LEVELS}

From baseline to year 1, there was a 3.6 percent increase in the level of low-density lipoprotein (LDL) cholesterol in the placebo group as compared with a 4.4 percent decrease in the level in the raloxifene group $(\mathrm{P}<0.001)$, and a 0.9 percent 


\begin{tabular}{|c|c|c|c|}
\hline \multirow[t]{2}{*}{ Adverse Event } & $\begin{array}{l}\text { Raloxifene } \\
(\mathrm{N}=5044)\end{array}$ & $\begin{array}{l}\text { Placebo } \\
(\mathrm{N}=5057)\end{array}$ & $P$ Value \\
\hline & \multicolumn{2}{|c|}{ number of participants (percent) } & \\
\hline Hot flushes & $401(8.0)$ & $244(4.8)$ & $<0.001$ \\
\hline Leg cramps & $489(9.7)$ & $341(6.7)$ & $<0.001$ \\
\hline Peripheral edema & $725(14.4)$ & $610(12.1)$ & $<0.001$ \\
\hline Gallbladder disease* & $230(5.6)$ & $186(4.5)$ & 0.03 \\
\hline Influenza-like syndrome & $21(0.4)$ & $31(0.6)$ & 0.17 \\
\hline Cataracts & $374(7.4)$ & $391(7.7)$ & 0.56 \\
\hline Benign gynecologic conditions $†$ & $102(2.0)$ & $107(2.1)$ & 0.74 \\
\hline Atrial fibrillation & $325(6.4)$ & $331(6.5)$ & 0.84 \\
\hline All cancers $\nmid$ & $286(5.7)$ & $281(5.6)$ & 0.79 \\
\hline Endometrial cancer $\mathbb{3}$ & $21(0.5)$ & $17(0.4)$ & 0.53 \\
\hline Uterine sarcoma & $1(<0.01)$ & 0 & - \\
\hline Ovarian cancer $\|$ & $17(0.4)$ & $10(0.2)$ & 0.17 \\
\hline
\end{tabular}

* This category includes cholecystitis, cholelithiasis, and miscellaneous other gallbladder diseases. Participants who reported having undergone a cholecystectomy at baseline (and who reported no subsequent gallbladder disease) were excluded. For this analysis, there were 4111 participants in the placebo group and 4144 in the raloxifene group.

$\uparrow$ This category includes benign cervical, uterine, vaginal, vulvar, and ovarian neoplasms, postmenopausal bleeding, uterine polyps, cysts, fibroids, hyperplasia, and other conditions.

†Tis category excludes breast cancer. The most commonly reported were gastrointestinal cancers (1.2 percent in each treatment group), basal-cell carcinoma (1.1 percent in each treatment group), reproductive cancers (placebo group, 0.7 percent; raloxifene group, 0.9 percent), and respiratory cancers (placebo group, 0.8 percent; raloxifene group, 0.7 percent). $\int$ Only women with an intact uterus were included - 3882 women in the placebo group and 3900 in the raloxifene group. 9 The one case was reported by the investigator as low malignant leiosarcoma.

$\|$ Only women with at least one ovary were considered - 4606 women in the placebo group and 4559 in the raloxifene group.

increase in the level of high-density lipoprotein (HDL) cholesterol in the placebo group as compared with a 2.3 percent increase in the level in the raloxifene group $(\mathrm{P}<0.001)$.

\section{DISCUSSION}

Treatment with raloxifene for a median of 5.6 years did not significantly affect the risk of coronary events. Such treatment decreased the risks of invasive breast cancer and clinical vertebral fracture and increased the risks of venous thromboembolic events and fatal stroke.

When the RUTH trial was designed, compelling evidence from many observational studies suggested that postmenopausal estrogen therapy was cardioprotective. ${ }^{5,6}$ However, three large trials of postmenopausal treatment with hormones ${ }^{7-9}$ subsequently failed to show a cardioprotective effect of estrogen, and the trials of estrogen plus progestin ${ }^{7,8}$ showed an early increased risk. We found that treatment with raloxifene did not sig- nificantly affect the risk of coronary events among women with CHD or among women at high risk for CHD, nor did it cause an early increase in the risk of CHD. These results confirm the results of the MORE trial, in which raloxifene had a null effect on coronary disease in postmenopausal women with osteoporosis, but they do not provide support for the cardioprotective effect observed in a post hoc analysis of women in the MORE trial who were at high cardiovascular risk. ${ }^{10}$ The narrow 95 percent confidence interval for the effect of raloxifene on the primary coronary outcome suggests that raloxifene is unlikely to reduce coronary risk more than 16 percent or to increase coronary risk more than 7 percent.

Raloxifene had moderate effects on LDL cholesterol and HDL cholesterol levels that were of a lesser magnitude than the changes achieved by other medications shown to be cardioprotective. ${ }^{17}$ The use of lipid-lowering medications, antihypertensive agents, and antiplatelet agents was encouraged in the RUTH trial and increased during 
the trial. The use of cardioprotective medications did not differ significantly between the treatment groups and is unlikely to explain the null results. However, the lower-than-expected rate of coronary events may reflect the substantial use of these medications.

Women in the raloxifene group had a 55 percent lower risk of estrogen-receptor-positive invasive breast cancer than did women in the placebo group (absolute risk reduction, 1.2 estrogen-receptor-positive invasive breast cancers per 1000 women treated for one year). This reduction is consistent with that observed in postmenopausal women in the MORE trial. ${ }^{13}$ The relative reduction in the risk of invasive breast cancer was also similar to that seen among women at increased risk for invasive breast cancer treated with tamoxifen in the Breast Cancer Prevention Trial. ${ }^{18}$ The effect of treatment with raloxifene in the RUTH trial was similar, regardless of the fiveyear predicted risk of invasive breast cancer, on the basis of the Gail score. ${ }^{16}$

Although participants in the RUTH trial were not selected on the basis of an increased risk of breast cancer, 41 percent had a five-year predicted risk of 1.66 percent or greater ${ }^{16}$ (Table 1). This estimated risk would have made them eligible for the Breast Cancer Prevention Trial and the Study of Tamoxifen and Raloxifene (STAR). ${ }^{18,19}$ The STAR results indicate that raloxifene is as effective as tamoxifen in reducing the risk of invasive breast cancer among women at increased risk for invasive breast cancer but is associated with fewer uterine cancers and venous thromboembolic events. ${ }^{19}$

Results of RUTH and previous trials ${ }^{13,20}$ show that raloxifene does not reduce the risk of estrogen-receptor-negative invasive breast cancer. The mechanism whereby raloxifene reduces the risk of estrogen-receptor-positive invasive breast cancer is not clear but is probably related to estrogen antagonism resulting in regression of subclinical estrogen-receptor-positive cancers.

Raloxifene did not increase the overall risk of stroke but was associated with a 49 percent increase in the incidence of fatal stroke. Raloxifene had no significant effect on the overall risk of death from cardiovascular causes or death from any cause. There was no effect of raloxifene on the risk of stroke in the MORE trial. ${ }^{10}$ Tamoxifen increased the risk of stroke in most $\mathrm{t}^{18,21-23}$ but not all ${ }^{24}$ trials. In STAR, ${ }^{19}$ the incidence of stroke was similar in the raloxifene and tamoxifen groups.

In the WHI trials, estrogen alone or with a progestin increased the risk of stroke by approximately 40 percent in healthy postmenopausal women. ${ }^{8,9}$ Among women with a recent history of stroke or transient ischemic attack, estrogen did not affect the risk of nonfatal stroke but increased the risk of fatal stroke. ${ }^{25}$

Consistent with the findings of previous trials of estrogen and SERMs, ${ }^{7-9,18,26}$ we found that raloxifene use was associated with an increased risk of venous thromboembolic events. There was a 35 percent reduction in the risk of clinical vertebral fractures but no significant reduction in nonvertebral fractures in the raloxifene group, consistent with results in the MORE trial. ${ }^{27}$

Hot flushes, leg cramps, and peripheral edema, all known to be associated with raloxifene use, ${ }^{20,28}$ were reported more frequently by women assigned to raloxifene. Raloxifene did not increase the risk of all nonbreast cancers, including endometrial cancer. The higher incidence of reported gallbladder disease was not observed in the study by Grady et al. ${ }^{26}$ but is a recognized complication of oral hormone therapy. ${ }^{29}$ Rates of cholecystectomy were unrelated to the treatment assignment.

In conclusion, in postmenopausal women with CHD or at increased risk for CHD, treatment with raloxifene for a median of 5.6 years reduced the risk of invasive breast cancer and did not change the incidence of coronary events. In these women, the difference in the absolute rates of events that were decreased (i.e., breast cancer and clinical vertebral fractures) was similar to the difference in the absolute rates of events that were increased (i.e., venous thromboembolic events and fatal strokes). When considering the use of raloxifene in a postmenopausal woman, the clinician should take into account the individual woman's risk of disease and her personal preferences and weigh potential benefits against risks and against the availability of alternative interventions.

Supported by Eli Lilly, Indianapolis.

Dr. Barrett-Connor reports having received salary support from Eli Lilly for serving as principal investigator and as an investigator at a clinical site for the RUTH trial; having served on paid advisory boards for Merck, Eli Lilly, Procter \& Gamble, and Amgen; and having received grant support from Amgen. Dr. Mosca reports having received consulting fees from Eli Lilly and Organon. Dr. Collins reports having received consulting fees from Eli Lilly, Berlex, Merck, Pantarhei, and Pfizer; having received lecture fees from Berlex, Merck, Pfizer, Novo Nordisk, 
and Organon; and having received grant support from Eli Lilly, Organon, and Merck. Dr. Grady reports having received salary support, by means of contracts with the University of California, San Francisco, from Berlex, Eli Lilly, Merck, Pfizer, and WyethAyerst Research and consulting fees for chairing a data and safety monitoring board at Organon. Dr. Kornitzer reports having received grant support and lecture fees from Eli Lilly, Merck, Bristol-Meyers Squibb, Sandoz, and AstraZeneca. Dr. Wenge reports having received salary support from Eli Lilly for serving as coprincipal investigator and as principal investigator at a clinical site for the RUTH trial; having received consulting fees from Eli Lilly, CV Therapeutics, NitroMed, Schering-Plough, and the Leadership Council for Improving Cardiovascular Care; having received speaker's fees from Pfizer, Novartis, Merck, Eli Lilly, and NitroMed; and having received research grants or contracts or having served on trial steering committees for Eli Lilly, AstraZeneca, and Pfizer. Dr. Geiger and Ms. McNabb are full-time employees and stockholders of Eli Lilly. No other potential conflict of interest relevant to this article was reported.

We are indebted to the 10,101 women, the investigators, and the staff for their dedication and commitment to the RUTH trial; to Lisa Houterloot and Steve Zheng for statistical programming; to Jingli Song and Messan Amewou-Atisso for statistical analysis; to Mindy Rance for assistance with figures and the preparation of the manuscript; and to Sherie Dowsett for input into the scientific content.

\section{APPENDIX}

The following people participated in the RUTH trial: Adjudicators: Coronary Primary Outcome Committee: Belgium - L. Pierard, H. Kulbertus; Italy - A. Maggioni, S. DiLuzio; United Kingdom - D. Julian (Chair), J. Hampton; United States - R. O'Rourke, R. Naidu, T. Ryan, D. Weiner; Central ECG Laboratory Committee: Germany — R. Schroeder; Breast Cancer Outcome Committee: United States — K. Miller (Chair), V. Jackson, S.C. Lottich; Secondary Outcome Committee: United Kingdom - K. Khaw (Chair); Stroke Committee: France — D. Leys; United States — D. Sherman; Venous Thromboembolism Outcome Committee: Canada — W. Geerts, A. Turpie; United Kingdom - N. Poulter; United States - D. Green; Data Safety Monitoring Board: France - J.-P. Boissel; United Kingdom - A. Howell; United States - J. Wittes (Chair), N. Davidson, D. DeMets, R. Frye, S. Oparil, E. Rappaport; Investigators: Argentina - A. Becerra, J.R. Zanchetta, N.O. Siseles; Belgium - M. Renard, C. Van de Weghe, F. Van den Branden, E. Weber, J. Bosmans, D. El Allaf, G. de Backer, G. Heyndrickx, J. Boland, J. Ducobu; Brazil - A. Afiune, A.C. Carvalho, C. Drumond, J.F. Ramirez, O.R. Coelho, O.T. Greco; Canada - A. Cheung, B. Abramson, C.K. Yuen, G. Tremblay, M. Arnold, N. Robitaille, R. Aronson, R.S. Boroditsky, R. Vexler, T.C. Monchesky, T.J. Anderson, V. Bernstein; Czech Republic - B. Filipensky, J. Bultas, J. Florian, J. Kvasnicka, L. Kamenik, M. Branny, M. Choura, M. Tomanova, O. Mayer, Sr., R. Cifkova; Denmark - A. Prange, C. Christiansen, G. Jensen, K. Kolendorf, K. Lyngborg, K. Sorensen, O. Faergemann, P. Grande, T. Jensen, T.L. Svendsen; Finland - H. Oksa, J. Melin, L. Voipio-Pulkki, M. Tikkanen, P. Satomaa; France - B. Charbonnel, B. Verges, F. Berthezene, C. Libersa, D. Thomas, F. Paillard, H. Hanaire-Broutin, I. Macquin-Mavier, J. Bonnet, J. Puel, P. Moulin; Germany - B. Grosch, B.O. Böhm, C. Gohlke-Baerwolf, H.G. Fritz, H. Klepzig, H. Sigel, J. Brachmann, J. Cyran, J. Senges, K.H. Usadel, K. Badenhoop, M. Gottwik, U. Sechtem, W. Delius; Hungary - F. Lakatos, G. Kakuk, I. Czuriga, I. Jszsef, J. Polyak, K. Karlocai, L. Gabos, P. Kempler; Ireland - B. Macmahon, F. Lavin; Israel - B.A. Lewis, B. Koifman, L. Reisin, M. Moriel, M. Shechter, N. Cohen-liel, N. Roguin, S. Caspi, Z. Vered; Italy - A. Branzi, A. L’Abbate, C. Fossati, D. Cucinotta, F. Santeusanio, G. Pozza, L. Saccà, M. Modena, R. Fanelli, R. Giorgino, S. Chierchia; Mexico - C. Aguilar, G. Llamas, J. Cervantes, R. Velasco, S. Olvera; the Netherlands - A.G. De Vries, A. Maas, D. Lok, H. Suryapranata, I. Stoel, J.H. Kingma, J.L. Posma, G. Bartels, M.A. Galjee, N. Holwerda, P. Dunselman; Norway - E.S. Oefjord, H. Haugland, J.A. Stakkestad, J. Halse, L. Woie, P. Lund-Johansen, T. Soerdal; Poland - E. Marcinowska-Suchowierska, J. Badurski, J. Klos, J. Ogonowski, K. Hoszowski, M. Krzeminska-Pakula, M. Tendera, W. Pluta, Z. Kornacewicz-Jach; Russia - A.A. Lyakishev, R.G. Oganov, V.O. Konstantinov, V.S. Gurevich; Singapore — Y.T. Lim; South Africa — J. Bayat, L.A. Distiller, M. Conradie, M.E. Seeber, P. Commerford, S. Cassim; Spain - A. Llacer, J. Cruz-Fernandez, J. Farrerons, J. Gomez Doblas, J. Velasco-Rami, L. Lopez-Bescos, L. Martin Jadraque, J.R. Rey Blás, R.M. Lidon, R. Martos Ferres; Sweden - E. Swahn, G. Samsioe, H. Berglund, J. Herlitz, K. Schenck-Gustafsson, K. Tolagen, N. Johnston, P. Henriksson; Switzerland - F. Follath, O. Bertel; Taiwan - J. Cheng, J.H. Chen, M. Mao-Young-Fu, W. Chen, W. Cherng, W. Sheu, Y. Lee; United States - C.S. Duvernoy, D. Herrington, E. Barrett-Connor (principal investigator), J.A. Cauley, K.E. Ensrud, M. Greenwald, N. Wenger (coprincipal investigator), L. Mosca, R. Knopp; United Kingdom - H.A. Last, J. Fraser, J. Robinson, P. Collins, R. Gray; Executive Committee: E. Barrett-Connor, P. Collins, D. Grady, M. Kornitzer, L. Mosca, N. Wenger.

\section{REFERENCES}

1. Fuchs-Young R, Glasebrook AL, Short $\mathrm{LL}$, et al. Raloxifene is a tissue-selective agonist/antagonist that functions through the estrogen receptor. Ann N Y Acad Sci 1995;761:355-60.

2. Delmas PD, Bjarnason NH, Mitlak $\mathrm{BH}$, et al. Effects of raloxifene on bone mineral density, serum cholesterol concentrations, and uterine endometrium in postmenopausal women. N Engl J Med 1997; 337:1641-7.

3. Walsh BW, Kuller LH, Wild RA, et al Effects of raloxifene on serum lipids and coagulation factors in healthy postmenopausal women. JAMA 1998;279:1445-51.

4. Walsh BW, Paul S, Wild RA, et al. The effects of hormone replacement therapy and raloxifene on C-reactive protein and homocysteine in healthy postmenopausal women: a randomized, controlled trial. J Clin Endocrinol Metab 2000;85:214-8.

5. Stampfer MJ, Colditz GA. Estrogen replacement therapy and coronary heart disease: a quantitative assessment of the epidemiologic evidence. Prev Med 1991;20 47-63.

6. Grady D, Rubin SM, Petitti DB, et al. Hormone therapy to prevent disease and prolong life in postmenopausal women. Ann Intern Med 1992;117:1016-37.

7. Hulley S, Grady D, Bush T, et al. Randomized trial of estrogen plus progestin for secondary prevention of coronary heart disease in postmenopausal women. JAMA 1998;280:605-13.

8. Writing Group for the Women's Health Initiative Investigators. Risks and bene fits of estrogen plus progestin in healthy postmenopausal women: principal results from the Women's Health Initiative randomized controlled trial. JAMA 2002;288: 321-33.

9. Anderson GL, Limacher M, Assaf AR, et al. Effects of conjugated equine estrogen in postmenopausal women with hysterectomy: the Women's Health Initiative randomized controlled trial. JAMA 2004; 291:701-12.

10. Barrett-Connor E, Grady D, Sashegyi A, et al. Raloxifene and cardiovascular events in osteoporotic postmenopausal women: four-year results from the MORE (Multiple Outcomes of Raloxifene Evaluation) randomized trial. JAMA 2002;287:84757.

11. Brzozowski AM, Pike ACW, Dauter Z, et al. Molecular basis of agonism and an- 
tagonism in the oestrogen receptor. Nature 1997;389:753-8.

12. Anzano MA, Peer CW, Smith JM, et al Chemoprevention of mammary carcinogenesis in the rat: combined use of raloxifene and 9-cis-retinoic acid. J Natl Cancer Inst 1996;88:123-5.

13. Cauley JA, Norton L, Lippman ME, et al. Continued breast cancer risk reduction in postmenopausal women treated with raloxifene: 4-year results from the MORE trial. Breast Cancer Res Treat 2001;65:12534. [Erratum, Breast Cancer Res Treat 2001 67:191.]

14. Mosca L, Barrett-Connor E, Wenge NK, et al. Design and methods of the Raloxifene Use for The Heart (RUTH) study. Am J Cardiol 2001;88:392-5.

15. Wenger NK, Barrett-Connor E, Collins P, et al. Baseline characteristics of participants in the Raloxifene Use for The Heart (RUTH) trial. Am J Cardiol 2002;90:120410.

16. Costantino JP, Gail MH, Pee D, et al Validation studies for models projecting the risk of invasive and total breast cancer incidence. J Natl Cancer Inst 1999;91: 1541-8.

17. Pasternak RC. The ALLHAT lipid lowering trial - less is less. JAMA 2002;288 3042-4.
18. Fisher B, Costantino JP, Wickerham DL, et al. Tamoxifen for prevention of breast cancer: report of the National Sur gical Adjuvant Breast and Bowel Project P-1 Study. J Natl Cancer Inst 1998;90:137188.

19. Vogel VG, Costantino JP, Wickerham $\mathrm{DL}$, et al. Effects of tamoxifen vs raloxifene on the risk of developing invasive breas cancer and other disease outcomes: the NSABP Study of Tamoxifen and Raloxifene (STAR) P-2 trial. JAMA 2006;295:2727-41. 20. Martino S, Cauley JA, Barrett-Connor E, et al. Continuing outcomes relevant to Evista: breast cancer incidence in post menopausal osteoporotic women in a randomized trial of raloxifene. J Natl Cancer Inst 2004;96:1751-61.

21. Braithwaite RS, Col NF, Wong JB. Estimating hip fracture morbidity, mortality and costs. J Am Geriatr Soc 2003;51:3 64-70.

22. Bushnell CD, Goldstein LB. Risk of ischemic stroke with tamoxifen treatment for breast cancer: a meta-analysis. Neurology 2004;63:1230-3.

23. Dignam JJ, Fisher B. Occurrence of stroke with tamoxifen in NSABP B-24. Lancet 2000;355:848-9.

24. Geiger AM, Fischberg GM, Chen W, Bernstein L. Stroke risk and tamoxifen therapy for breast cancer. J Natl Cancer Inst 2004;96:1528-36.

25. Viscoli CM, Brass LM, Kernan WN, Sarrel PM, Suissa S, Horwitz RI. A clinical trial of estrogen-replacement therapy af ter ischemic stroke. N Engl J Med 2001; 345:1243-9.

26. Grady D, Ettinger B, Moscarelli E, et al. Safety and adverse effects associated with raloxifene: multiple outcomes of raloxifene evaluation. Obstet Gynecol 2004;104 837-44

27. Delmas PD, Ensrud KE, Adachi JD, et al. Efficacy of raloxifene on vertebral fracture risk reduction in postmenopausal women with osteoporosis: four-year results from a randomized clinical trial. J Clin Endocrinol Metab 2002;87:360917.

28. Ettinger B, Black DM, Mitlak BH, et al. Reduction of vertebral fracture risk in postmenopausal women with osteoporosis treated with raloxifene: results from a 3-year randomized clinical trial. JAMA 1999;282:637-45. [Erratum, JAMA 1999; 282:2124.]

29. Cirillo DJ, Wallace RB, Rodabough RJ, et al. Effect of estrogen therapy on gallbladder disease. JAMA 2005;293:330-9.

Copyright (c) 2006 Massachusetts Medical Society.

\section{JOURNAL EDITORIAL FELLOW}

The Journal's editorial office invites applications for a one-year research fellowship beginning in July 2007 from individuals at any stage of training. The editorial fellow will work on Journal projects and will participate in the day-to-day editorial activities of the Journal but is expected in addition to have his or her own independent projects. Please send curriculum vitae and research interests to the Editor-in-Chief, 10 Shattuck St., Boston, MA 02115 (fax, 617-739-9864), by October 1, 2006. 